\title{
Políticas públicas, economicidade e judicialização da saúde
}

\author{
Public policies, economy and judicialization of health \\ Políticas públicas, economicidad y judicialización de la salud
}

\section{Resumo}

O fenômeno da judicialização da saúde fez crescer o número de demandas levadas à apreciação dos órgãos judiciais em todo o Brasil. No município de Mossoró/RN, a população busca o Poder Judiciário para ver garantido seu direito à realização de procedimentos cirúrgicos de toda natureza, como é o caso, por exemplo, das cirurgias eletivas. O presente trabalho objetivou compreender os fatores que levam à judicialização, mesmo nos casos em que o procedimento cirúrgico é oferecido através do Sistema Único de Saúde. Utilizando a metodologia quali-quantitativa, e a partir do estudo realizado em 45 processos judiciais em trâmite nas Varas da Fazenda Pública de Mossoró/RN, além de entrevistas com profissionais atuantes. A pesquisa verificou a ocorrência de má gestão do dinheiro público quando, podendo aplicar alternativas de economicidade, o ente público municipal deixa que os juízes bloqueiem verba pública para custeio de procedimentos sem baratear os serviços. O estudo minucioso em quarenta e cinco processos judiciais, através de pesquisa quali-quantitativa, revelou a judicialização por serviços já fornecidos, além de procedimentos não contemplados nas políticas públicas de saúde, concessão desenfreada e ausência de um padrão no procedimento adotado entre os juízes atuantes nos processos judiciais.

Palavras-chave: Políticas públicas; Judicialização; Procedimentos cirúrgicos; Saúde.

\begin{abstract}
The phenomenon of the judicialization of health has increased the number of demands brought to the attention of judicial bodies throughout Brazil. In the municipality of Mossoró/ RN, the population seeks the Judiciary to see their right to perform surgical procedures of all kinds guaranteed, as is the case, for example, of elective surgeries. This study aimed to understand the factors that lead to judicialization, even in cases where the surgical procedure is offered through the Unified Health System (SUS). It is a qualitative and quantitative research, based on the study carried out in 45 court proceedings pending in the Courts of Fazenda Pública de Mossoró/RN, in addition to interviews with active professionals. The research verified the occurrence of mismanagement of public money when, being able to apply economical alternatives, the municipal public entity allows the judges to block public money for fund procedures without cheapening services. The detailed study of forty-five court proceedings, through qualitative and quantitative research, revealed judicialization for services already provided, in addition to procedures not covered by public health policies, unrestrained concession and the absence of a standard in the procedure adopted among judges in court proceedings.
\end{abstract}

Keywords: Public policy; Judicialization; Surgical procedures; Health.

\section{Resumen}

El fenómeno de la judicialización de la salud ha incrementado el número de demandas puestas en conocimiento de los órganos judiciales en todo Brasil. En el municipio de Mossoró / RN, la población busca que el Poder Judicial vea garantizado su derecho a realizar procedimientos quirúrgicos de todo tipo, como es el caso, por ejemplo, de las cirugías electivas. El presente estudio tuvo como objetivo conocer los factores que conducen a la judicialización, incluso en los casos en que el procedimiento quirúrgico se ofrece a través del Sistema Único de Salud. Utilizando la metodología cualitativa y cuantitativa, y con base en el estudio realizado en 45 juicios pendientes en los Juzgados del Erario Público de Mossoró / RN, además de entrevistas con profesionales en activo. La investigación verificó la ocurrencia de mala administración del dinero público cuando, al poder aplicar alternativas económicas, la entidad 
pública municipal permite a los jueces bloquear fondos públicos para financiar trámites sin abaratar los servicios. El estudio detallado de cuarenta y cinco juicios, a través de investigaciones cualitativas y cuantitativas, reveló judicialización por servicios ya prestados, además de trámites no contemplados en las políticas públicas de salud, concesión irrestricta y la ausencia de un estándar en el procedimiento adoptado entre los jueces en funciones en los procedimientos judiciales.

Palabras clave: Políticas públicas; Judicialización; Procedimientos quirúrgicos; Salud.

\section{Introdução}

A judicialização do acesso às políticas públicas e serviços de saúde é tema recorrente em discussões nos órgãos do Judiciário, Defensorias Públicas, Promotorias de Justiça e também no meio acadêmico, em razão de tratar demandas sociais recorrendo ao judiciário e que possui pontos de vista teórico-políticos divergentes entre os que estão envolvidos no debate desse tema. Sabe-se que o crescente número de demandas de saúde envolvendo a realização de procedimentos cirúrgicos tem sido um desafio para os gestores municipais, seja pela precariedade das instituições públicas, seja pela ausência de planejamento por parte dos chefes do executivo municipal. A desconstrução do Sistema Único de Saúde e as limitações de gastos imposta a essa área de serviços públicos têm agravado a possibilidade de cumprir a universalidade do acesso à saúde previsto nas normas constitucionais (Carvalho, 2016; Fonte, 2013).

Dessa forma, as políticas públicas também compreendem o conjunto de atos e fatos jurídicos que têm por finalidade a concretização da ação governamental em resposta às demandas sociais pela administração pública (Fonte, 2013).

Sob essa perspectiva, analisou-se a judicialização da saúde no município de Mossoró/RN, nos casos de realização de procedimentos cirúrgicos de toda natureza, ainda, as consequências da referida judicialização, considerando o posicionamento dos órgãos jurisdicionais, bem como a fundamentação jurídica apresentada pelo ente público municipal nas lides propostas pela população mossoroense usuária dos serviços do Sistema Único de Saúde - SUS.

Nas questões que envolvem dinheiro público espera-se que o Município, assim como nas três esferas de governo, quando demandado, busque solucionar as demandas da forma que menos onere o erário público ${ }^{1}$. Nesse sentido, questionou-se a realidade atual: Por que o ente público municipal, nas demandas propostas judicialmente, não busca a resolução por meio da conciliação? O bloqueio de verbas públicas é sempre necessário para que se obtenha a tutela específica através do resultado prático equivalente?

Dessa forma, objetivou-se esclarecer o porquê de a conciliação não ser a regra nos processos de saúde que tramitam nas Varas da Fazenda Pública de Mossoró-RN no período compreendido entre janeiro de 2017 a julho de 2018. Para isso, buscou-se conhecer a agenda pública municipal no que se refere às demandas de cirurgias, especialmente as eletivas traumatoortopédicas, analisando, especificamente, o tratamento dado ao tema pela Lei Orçamentária Anual - LOA.

\section{Metodologia}

Trata-se de uma pesquisa do tipo quali-quantitativa, e a partir do estudo realizado em 45 processos judiciais em trâmite nas Varas da Fazenda Pública de Mossoró/RN, no período supracitado e entrevistas estruturadas com profissionais atuantes (Oliveira, 2007; Rosa, 2008).

Posteriormente, analisamos a relação entre os dados estatísticos obtidos por meio de pesquisa quali-quantitativa (Godoy, 1995), visualizando a documentação processual no acervo das Varas da Fazenda Pública de Mossoró/RN, e os benefícios gerados pela conciliação nas demandas que visam a realização de procedimento cirúrgico-ortopédico e cirurgias de outras naturezas.

${ }^{1}$ Erário é o dinheiro disponível ao governo para gerir o país. É o conjunto de bens e valores, composto pelos recursos de natureza financeira, tesouro nacional, etc. 
Também, como parte do processo metodológico, realizamos entrevistas com uma Juíza do TJRN, uma Defensora Pública, um Procurador do Município e uma Professora de Direito, para apreendermos, do ponto de vista dos entrevistados, causas e consequências da judicialização da saúde no Município de Mossoró, Rio Grande do Norte.

A fim de entender mais precisamente o tema sob análise, a julgar pela complexidade, utilizou-se a pesquisa bibliográfica necessária, além de dados constantes dos processos envolvendo o direito à saúde ajuizados perante as Varas da Fazenda Pública da Comarca de Mossoró-RN. Esses processos demonstram a constante utilização do judiciário para que a população posso ter acesso aos serviços de saúde pública garantidos como obrigação do poder público.

\section{Resultados e Discussão}

Após a análise da agenda pública do município de Mossoró-RN e o tratamento dado às demandas para a realização de procedimentos cirúrgicos, verificou-se alinhamentos entre o PPA, a LDO e a LOA, no tocante, a internalização das demandas de cirurgias, especialmente as eletivas traumato-ortopédicas.

O Plano Plurianual (PPA) é produto de lei de iniciativa do Poder Executivo, o qual estabelece as diretrizes, os objetivos e as metas da administração pública municipal para as despesas de capital e outras delas decorrentes e para as relativas aos programas governamentais contínuos, conforme se infere do conceito descrito no sítio eletrônico da Prefeitura Municipal de Mossoró. De acordo com a Constituição Federal de 1988, o PPA deve ser elaborado no primeiro ano de uma gestão. É ele o instrumento coordenador de todas as ações governamentais e, como tal, direciona as Leis de Diretrizes Orçamentárias (LDO) e os Orçamentos Anuais (LOA), bem como todos os planos setoriais instituídos durante o seu período de vigência, que é de 4 (quatro) anos.

A Lei de Diretrizes Orçamentárias, por seu turno, compreende as metas e prioridades da administração pública contidas no Plano Plurianual, anteriormente elaborado, para o exercício financeiro do ano seguinte.

Por sua vez, a lei orçamentária anual compreenderá o orçamento fiscal referente aos Poderes do Município, seus fundos, órgãos e entidades da administração direta e indireta; o orçamento de investimento das empresas em que o Município, direta ou indiretamente, detenha a maioria do capital social com direito a voto; o orçamento da seguridade social, abrangendo todas as entidades e órgãos a ela vinculados, da administração direta ou indireta, bem como os fundos e fundações instituídos e mantidos pelo Poder Público. ${ }^{2}$

Através da Lei Orçamentária Anual é que o gestor municipal, chefe do executivo, terá direcionada parte da verba daquele determinado exercício financeiro. Segundo a referida Lei, a despesa total fixada nos Orçamentos Fiscal e da Seguridade Social para o exercício de 2017 foi de $\mathrm{R} \$$ 674.662.663,00 (seiscentos e setenta e quatro milhões, seiscentos e sessenta e dois mil, seiscentos e sessenta e três reais). Desse valor, $\mathrm{R} \$ 186.746 .000,00$ (cento e oitenta e seis milhões, setecentos e quarenta e seis mil reais) foram destinados ao Fundo Municipal de Saúde, para as questões afetas à saúde pública em Mossoró. ${ }^{3}$

A verba acima descrita é composta por receita tributária; receita patrimonial; transferências correntes (intergovernamentais); e receitas de capital (convênios). Exemplificando, todo o valor arrecadado com os impostos, remuneração de depósitos bancários, valores repassados pela União e Estado e os vinculados diretamente ao Sistema Único de Saúde formam o montante direcionado à saúde pública.

Oportunamente, esclarece-se que o financiamento dessas ações e serviços de saúde é atribuição dos três âmbitos de gestão do SUS, podendo o cidadão, segundo o Supremo Tribunal Federal, litigar contra qualquer dos entes políticos, observado o que dispõe a Constituição Federal e a Lei Orgânica da Saúde, Lei 8.080/90.

\footnotetext{
${ }^{2}$ Disponível em <https://www.mossoro.rn.leg.br/legislacao/leis-orcamentarias>.

${ }^{3}$ Disponível em <https://www.mossoro.rn.leg.br/banco-de-arquivos/loa-2017>.
} 
Segundo informações do Ministério da Saúde, os recursos oriundos da União destinados às ações e serviços de saúde de média e alta complexidade ambulatorial e hospitalar estão, atualmente, organizados em dois componentes: Limite Financeiro da Média e Alta Complexidade Ambulatorial e Hospitalar (MAC); Fundo de Ações Estratégicas e Compensação (FAEC). Os recursos financeiros são transferidos após a apuração da produção dos estabelecimentos de saúde registrada pelos respectivos gestores nos Sistemas de Informação Ambulatorial e Hospitalar SIA/SIH como se verifica da Portaria de Consolidação nº 6, 28 de setembro de 2017, art. 173, I e II.

Sousa (2013, p.204), vaticina que os serviços de saúde em Mossoró-RN estão organizados da seguinte forma:

O município exerce a Gestão Plena do Sistema Municipal, estando responsável pelas Unidades de Atenção Básica de Saúde e as Unidades de Atendimento Especializado. Além disso, responde pela contratação e pagamento de prestadores públicos e privados, pela avaliação e controle da rede de serviços de saúde municipal, como também por um sistema municipal de auditoria. Até o momento o município administra todas as suas UBS e Unidades de Pronto Atendimento (UPA) através da gestão pública.

Para exemplificar, a distribuição de medicamentos é feita através da Unidade Central de Agentes Terapêuticos UNICAT. O fornecimento é precedido de cadastramento do usuário do SUS. O órgão responsável pelas ações e serviços de saúde é a Secretaria Municipal de Saúde, que atua por meio dos hospitais públicos, Unidades de Pronto Atendimento (UPA), além das Unidades Básicas de Saúde, criadas para facilitar e municipalizar a saúde na cidade, a fim de intermediar o acesso da população aos medicamentos essenciais.

Os termos utilizados pela $\mathrm{LOA}^{4}$ para demonstrar a destinação da verba pública alocada para a Secretaria da Municipal de saúde são perceptivelmente genéricos, a saber, “Administração Geral”, R \$ 14.268.000,00; “Atenção Básica em Saúde”, R\$ 75.035.000,00; "Vigilância Sanitária”, R\$3.125.000,00.

Todavia, em pesquisa feita ao sítio eletrônico da Prefeitura Municipal de Mossoró-RN é possível encontrar, mais detalhadamente, de que forma o dinheiro público é gasto na cidade. Por exemplo, consta dos dados que de janeiro a dezembro de 2017 a secretaria municipal de saúde despendeu ${ }^{5}$ R \$ 187.771.654,18. Do montante, R \$ 15.355.500,91 foram destinados ao pagamento de despesas junto ao Cardiodiagnóstico LTDA, o Hospital Wilson Rosado, descrito como pagamento de "Programa - Média e Alta Complexidade" e “Ação - Contratação de Serviços de Saúde - Rede Privada”.

A descrição leva a considerar que os pagamentos se referem ao custeio de cirurgias de média e alta complexidade, como osteossíteses, artroplastias, meniscectomias, nefrolitotripsias, realizadas através do prestador privado, o Hospital Wilson Rosado.

Importa, aqui, constatar o valor alocado para o custeio dos procedimentos cirúrgicos definidos como sendo de urgência, emergência ou eletivos. A Lei Orçamentária Anual trata do tema ao prever $\mathrm{R} \$ 90.233 .000,00$ para o programa de “Média e Alta Complexidade Ambulatorial e Hospitalar", ou seja, praticamente metade do orçamento previsto para a Saúde no ano de 2017. No ano anterior a verba foi de apenas $\mathrm{R} \$ 8.050,900,00$.

Inexplicavelmente, contrariando as estatísticas acima descritas, cresceu, em 2017 o número de demandas ajuizadas nas Varas da Fazenda Pública de Mossoró/RN com o escopo de compelir a administração pública a providenciar a realização de procedimentos cirúrgicos. Como se pôde ver nos noticiários da cidade, a realização dessas cirurgias foi suspensa em razão de falta de pagamento aos prestadores credenciados, o que ensejou a inefetividade de uma política pública regularmente estabelecida e, consequentemente, a imprescindível intervenção do Poder Judiciário.

\footnotetext{
${ }^{4}$ Os dados foram retirados da Lei Orçamentária Anual com exercício em 2017. Disponível em: <https://www.mossoro.rn.leg.br/banco-de-arquivos/loa-2017>.

5 Despesas da Saúde Pública em 2017. Disponível em: http://187.19.199.132/transparencia/despesasdet.aspx?exercicio=2017\&mes=12\&pos $=0 \&$ fase=0 \&perfil=2\&nvl=2\&flt=Va68IxNxCesVsvy9F8w1gF0g\%2bHIPzfi7\&dt=20181028222834.
} 
Não obstante o repasse legal de verba pública do estado para a municipalidade, as cirurgias eletivas (ortopédicas) foram suspensas em Mossoró-RN no período compreendido entre os meses de setembro de 2016 a outubro de 2017. Após quase 01 (um) ano de paralisação, o retorno dos procedimentos foi comemorado ${ }^{6}$ pelos edis além de celebrado pela população mossoroense, sobretudo pelos pacientes da extensa fila de espera das cirurgias.

Em 16 de agosto de 2017 o site Mossoró Hoje publicou reportagem onde divulgou a aprovação de Termo de Cooperação entre a Secretaria de Estado da Saúde (SESAP), Secretaria Municipal de Saúde de Natal e a Secretaria municipal de Saúde de Mossoró. O referido termo destinaria cerca de 18 milhões para resolução de questões relativas à saúde.

Em contrapartida, um vereador tornou pública, em sessão ocorrida no dia 13 de junho de 2018 a falta de repasses aos prestadores conveniados, por exemplo, o Hospital Wilson Rosado, o que ensejou, repetidamente, a paralisação das cirurgias ortopédicas em Mossoró-RN no início de 2018. Assim, a suspensão nos repasses de verba, eventualmente, além da ausência de cooperação horizontal são, nitidamente, alguns dos elementos que tem dificultado a continuidade das políticas públicas no âmbito da saúde municipal.

Outro ponto relevante, dentre os tantos relacionados à saúde municipal, Sousa (2013) justifica a irregularidade e descontinuidade das políticas públicas a partir de um prisma diferente ao afirmar que, historicamente, os gestores municipais utilizam os serviços públicos como moeda de troca para conseguirem voto e apoio político.

Nessa perspectiva, a utilização política dos serviços públicos se torna um dos maiores e mais complexos empecilhos à efetividade do direito à saúde em âmbito municipal, tendo em vista que, condicionar a criação e a implantação de uma política pública a promessas de apoio eleitoral viola diretamente o princípio da supremacia do interesse público, a que a administração pública está vinculada, e prejudica, indubitavelmente, a coletividade.

O sistema público de saúde brasileiro é um dos maiores do mundo e a forma adotada pelo poder público quando da implantação do Sistema Único de Saúde no tocante à sua gestão foi a solidariedade e a participatividade entre as três esferas de governo da federação. O referido Pacto de Gestão do SUS, estabelecido e delineado pela Portaria n ${ }^{\circ} 399$, de 22 de Fevereiro de 2006 menciona "as responsabilidades claras de cada ente federado de forma a diminuir as competências concorrentes e a tornar mais claro quem deve fazer o quê, contribuindo, assim, para o fortalecimento da gestão compartilhada e solidária do SUS". ${ }^{7}$

Embora inspirado no National Healt Service, o sistema público de saúde da Inglaterra, a realidade brasileira demonstra que o sistema brasileiro não logrou êxito como pretendia em se tratando da efetividade de sua implantação e universalização de seu acesso.

Vários são os fatores que contribuem para a inefetividade do sistema de saúde pública brasileiro. Dentre os problemas específicos que afligem o SUS, verifica-se, por exemplo, a insuficiência de médicos especialistas, somado à má distribuição dos profissionais à disposição; Segundo dados do Conselho Federal de Medicina (CFM) e do Instituto Brasileiro de Geografia e Estatística (IBGE) existe 1 médico para cada 470 habitantes. No entanto, nas regiões Norte e Nordeste, a quantidade é muito menor e chega a 1 médico para cada 953,3 e 749,6 brasileiros, respectivamente. ${ }^{8}$

Acrescente-se a isso o subfinanciamento e a má gestão dos recursos disponíveis. Dados levantados pela organização Contas Abertas, a requerimento do Conselho Federal de Medicina (CFM $)^{9}$, esclarecem que cerca de R $\$ 174$ bilhões deixaram de ser investidos pelo Ministério da Saúde entre os anos de 2003 e 2017.

6 Disponível em: <http://www.fecamrn.com.br/vereadores-comemoram-volta-das-cirurgias-eletivas-em-mossoro/>.

7 Disponível em: <http://bvsms.saude.gov.br/bvs/saudelegis/gm/2006/prt0399_22_02_2006.html>..

8 Disponível em: <https://g1.globo.com/educacao/guia-de-carreiras/noticia/n-de-habitantes-por-medico-no-norte-e-quase-3-vezes-o-do-sudeste-veja-o-raio-Xda-carreira.ghtml >..

9 Disponível em: <http://www.portal.cfm.org.br/index.php?option=com_content\&view=article\&id=27574:as-dificuldades-do-sus\&catid=46>. 
Esse valor equivale a apenas $11 \%$ do total autorizado para o Ministério da Saúde no Orçamento Geral da União (OGU) durante tal período (cerca de R \$ 1,6 trilhão). Como consequência, a repercussão do mau uso das verbas disponíveis reverbera, também, no sucateamento da infraestrutura.

Assim, considerando o decurso de 30 anos desde a criação do SUS, é necessário buscar os meios que viabilizem a sobreposição dessas barreiras, as quais impedem que o sistema público de saúde preste um serviço caracterizado pela qualidade e eficiência junto à população brasileira.

Dada a atribuição comum entre União, Estados e Municípios para executar políticas de saúde, os serviços e ações do Sistema Único de Saúde são, da mesma forma, de responsabilidade das três esferas de Governo. O poder político, assim entendido o chefe do Executivo, tem a competência de criar novas políticas públicas de acordo com a demanda social, como também executar adequadamente as já existentes.

Quando o poder público não assume seu dever legal de promover, de forma universal e igualitária o acesso da população à saúde pública de qualidade, e não comprova que o orçamento previsto é insuficiente para financiá-lo, o Poder Judiciário acaba sendo provocado a interferir na competência precípua do Executivo, obrigando este a oferecer à população, mediante políticas sociais e econômicas, a promoção, proteção ou recuperação de um direito individualmente tutelado, conforme vaticinam as Leis 8.080/90 e 8.142/90, além de todo o aparato constitucional trazido pela Carta Magna.

No município de Mossoró/RN, notadamente no ano de 2017, observou-se um crescente número de ações objetivando o fornecimento de medicamentos e a realização de procedimentos cirúrgicos de média e alta complexidade.

No que toca aos processos objetivando exigir do ente público municipal que proceda com a realização de algum procedimento cirúrgico, como é o caso das cirurgias ortopédicas de natureza eletiva, após uma detalhada análise em dados das referidas ações, constatou-se que quando a conciliação é utilizada na resolução dos litígios, chega-se ao resultado pretendido pelo autor ${ }^{10}$, qual seja, a realização da cirurgia, o Município, enquanto demandado, barateia o serviço junto aos prestadores habilitados do SUS, ainda que em rede privada, e, consequentemente, o erário público não é onerado como nas situações em que o bloqueio judicial é o primeiro mecanismo utilizado pelo julgador para dirimir controvérsias dessa natureza. Assim, comprova-se que a conciliação inicial, quando admitida pelas partes e incentivada pelo julgador, é o meio mais eficaz e menos oneroso para que se chegue ao pretenso resultado.

O crescimento no número de demandas visando um exercício digno do direito à saúde tem vários fatores, dentre eles o pensamento social de que "entrar na justiça" é a única forma de ver seu direito assegurado. O Judiciário, por sua vez, concede, liminarmente, a antecipação de tutela fundamentada na urgência comprovada através prescrição médica e outros meios de prova.

De forma diversa, em outros casos, após receber a petição inicial o magistrado, antes de analisar o pedido de antecipação de tutela, intima o gestor do SUS no âmbito municipal, amparado no Enunciado 13 da I Jornada de Direito à Saúde do Conselho Nacional de Justiça ${ }^{11}$, a fim de que se manifeste sobre o pedido, como se verifica no processo de ${ }^{\circ} 0818330$ 95.2017.8.20.5106 em trâmite na $2^{\mathrm{a}}$ Vara da Fazenda Pública:

Nessa esteira, recomenda-se, antes de analisar o pedido de tutela de urgência e, sempre que possível, a prévia oitiva do gestor do SUS, conforme vaticina o Enunciado 13 da I Jornada de Direito à Saúde do CNJ, in verbis: "Nas ações de saúde, que pleiteiam do poder público o fornecimento de medicamentos, produtos ou tratamentos, recomenda-se, sempre que possível, a prévia oitiva do gestor do Sistema único de Saúde(SUS), com vista a, inclusive, identificar solicitação prévia do requerente à Administração, competência do ente federado e alternativas terapêuticas".

\footnotetext{
${ }^{10}$ Autor é aquele que move uma ação judicial contra alguém. Nos casos ora tratados, o autor é um cidadão que necessita da interv enção do poder judiciário para conseguir um medicamento ou realizar cirurgia.

${ }^{11}$ As Jornadas de Direito à Saúde são promovidas pelo Conselho Nacional de Justiça e visam debater os problemas da judicialização da saúde, além de apresentar enunciados interpretativos sobre o tema. O evento decorre das ações do Fórum Nacional do Judiciário para a Saúde, que foi criado em 2010 , pelo CNJ. Sua criação foi necessária diante do crescente número de litígios levados ao judiciário, bem como pelo impacto dessas ações no orçamento público.
} 
Dessa maneira, o magistrado oportuniza ao ente público, inclusive, buscar os meios necessários para que o resultado pretendido pelo autor, enquanto usuário do Sistema Único de Saúde, seja satisfeito da maneira menos gravosa ao erário público.

Após isso, o magistrado analisará, caso a caso, acerca do deferimento ou não da tutela de urgência, avaliando até mesmo se houve a negativa de atendimento por parte do ente público. Na hipótese de deferimento do pedido inicial mediante decisão judicial, conceder-se-á prazo para seu cumprimento, além de autorização para contratar os serviços objetos da decisão mediante dispensa de licitação, nos termos do art. 24, inciso IV, da Lei Federal 8.666/93.

Ademais, a fim de assegurar o cumprimento de suas decisões com o resultado pretendido ou o seu equivalente prático, o magistrado adverte que o descumprimento da ordem judicial acarretará o bloqueio de verbas públicas no montante orçado necessário ao custeio do procedimento pleiteado.

Isso se dá uma vez que os procedimentos cirúrgicos pleiteados judicialmente estão previstos em Portarias do SUS, o que gera ao cidadão o direito de exigi-las no âmbito do Poder Judiciário. Na prática, o demandante demonstra seu direito por meio da tabela unificada constante do Sistema de Gerenciamento da Tabela de Procedimentos, Medicamentos, Órteses, Próteses e Materiais do SUS (SIGTAP). ${ }^{12}$

Ato contínuo, o Município de Mossoró-RN, quando demandado, contesta as ações propostas exclusivamente em face de um ente público, alegando que a competência para promover a saúde da população é solidária. Noutro ponto, culpa o judiciário de criar um "sistema paralelo ao SUS", e que virou prática habitual entre os magistrados o deferimento absoluto de pedidos relacionados à saúde sem observar o caso concreto.

Outra situação vista na análise processual, é a inclusão dos feitos imediatamente em pauta de audiência. O procedimento adotado utiliza o mesmo fundamento, o Enunciado 13 da I Jornada de Direito à Saúde do Conselho Nacional de Justiça, entretanto, ao invés de intimar o gestor para que se manifeste nos autos por meio de petição, o juiz notifica as partes para que compareçam à audiência de conciliação.

O procedimento é a regra adotada na $1^{\text {a }}$ Vara da Fazenda Pública da Comarca de Mossoró-RN, ocasião em que, de pronto, o magistrado esclarece que a conciliação em audiência tem trazido resultados positivos para ambas as partes. Sendo aceita a conciliação, o juiz determina que a parte autora compareça aos hospitais Wilson Rosado e São Luiz para novas avaliações médicas. Ao final, os prestadores privados deverão enviar orçamentos atualizados. O Hospital que orçar o procedimento em valor mais baixo será o licitante vencedor para realizar a cirurgia.

Comprovadamente, as transações em audiência têm impedido que o gasto do município com as cirurgias pelas vias judiciais se torne mais oneroso para o erário público. Prova disso é a conclusão da pesquisa feita em 45 processos que tramitaram nas três Varas da Fazenda Pública de Mossoró-RN entre 2017 e 2018.

Somando-se o valor dos orçamentos anexados aos autos pelos autores tem-se o montante de $\mathrm{R} \$ 1.136 .803,05$. Na conciliação, por meio do desconto obtido pelo ente público junto aos prestadores privados, chegou-se ao somatório final de $\mathrm{R} \$$ 779.355,62. Isso significa uma economia de $\mathrm{R} \$ 357.447,43$, ou seja 31,4\% economizados dos cofres públicos.

Ainda em 2017, as despesas decorrentes de ordens judiciais relativas a questões de saúde somam R\$1.891.716,52. Desse valor, R\$ 862.844,53 foram pagos à empresa Serviços De Assistência Médica e Ambulatorial LTDA (SAMA), estabelecimento especializado no fornecimento de mão de obra médica, especialmente para realização das cirurgias ortopédicas. Os dados foram retirados do Portal da Transparência da Prefeitura Municipal de Mossoró-RN.

12 Sistema de Gerenciamento da Tabela de Procedimentos, Medicamentos, Órteses, Próteses e Materiais do SUS (SIGTAP) é a tabela unificada onde constam os procedimentos cirúrgicos fornecidos através do Sistema Único de Saúde (SUS). Constam, ainda, informações como modalidade de atendimento, complexidade e financiamento. Disponível em: <http://sigtap.datasus.gov.br/tabela-unificada/app/sec/inicio.jsp>. Acesso em: 31 Out 2018. 
Por meio de normas, atividades e programas é que as políticas públicas, forma de como o Estado, representado pelos três poderes, alcançam seus objetivos e valores perseguidos pela sociedade através da constituinte de 1988.

A judicialização da saúde em Mossoró-RN remete, naturalmente, à avaliação das políticas públicas segundo os indicadores de eficácia, eficiência e efetividade. A utilização dos 3E's como metodologia de verificação do desempenho de uma ação pública social é indispensável para averiguar quais as metas e se foram atingidas (resultado); quais os benefícios frente ao custo despendido (custo-benefício); e o impacto social. Sua relevância é destacada por diversos autores, dentre eles Antico e Jannuzzi (2006); Arretche (1999) e Secchi (2016).

Constata-se a inefetividade de uma política pública, por exemplo, a partir de uma análise minuciosa da transformação ocorrida a partir das ações implementadas. É preciso responder se houve impacto social com a implantação de uma política pública. Dessa forma, caso os efeitos produzidos não sejam os esperados, será necessário o replanejamento das ações da política pública avaliada.

Nas palavras ${ }^{13}$ de João Pedro Gebran Neto, Desembargador do Tribunal Regional Federal da $4^{\text {a }}$ Região:

Os principais problemas são relacionados à desorganização do Sistema de Saúde. A judicialização transfere para o juiz o poder de deliberar sobre políticas públicas de saúde, e essas deliberações, via de regra, tem sido do ponto de vista individual, concedendo para indivíduos direitos que não estão plasmados nas políticas públicas de saúde. Isso acaba fazendo com o que o Poder Judiciário seja quem decide aonde aplicar e para quem, ao invés de ser feito de modo global, de modo harmônico, para atender à maioria ou a todos que precisem.

Portanto, é evidente a expansão da atuação do judiciário, sobretudo nas situações em que o Poder Legislativo não consegue atuar. O ingresso no judiciário, então, é uma das maneiras que os cidadãos se valeram para salvaguardar o exercício de seus direitos.

Nesse viés, é pertinente a compreensão de que o crescimento no número de demandas judiciais é ocasionado por irregularidades e imperfeições no sistema de políticas públicas de saúde, mormente na padronização e dispensação dos medicamentos, o que produz judicialização desenfreada e preferência de necessidades individuais em detrimento da coletividade.

A fim de entender outros aspectos do tema da judicialização a partir do ponto de vista de profissionais que atuam em Mossoró/RN, elaborou-se um roteiro de entrevista com 06 (seis) questões abertas, nas quais os respondentes ficaram livres para se posicionarem, com suas próprias palavras, sobre os subtemas tratados especificamente em cada indagação.

Primeiramente, questionou-se quais fatores contribuem para o fenômeno da judicialização do direito à saúde em Mossoró-RN. Na óptica da Defensora Pública titular da $5^{\text {a }}$ Defensoria Cível de Mossoró/RN:

A judicialização da saúde ocorre em razão da necessidade de se garantir o acesso universal e igualitário da população aos serviços de saúde, que, muitas vezes, esbarra em diligências burocráticas, na falta de informações e em entraves financeiros que tornam esses serviços deficientes. Some-se a isso a urgência e imediaticidade das providências médicas, a fim de resguardar o bem da vida e preservar a dignidade da pessoa humana.

Portanto, a necessidade e urgência das demandas de saúde, assim como o dever atribuído aos Entes Públicos, reiteradamente descumprido, de efetivar o direito à saúde e assegurar o mínimo existencial, por meio de ações preventivas e do fornecimento gratuito, contínuo e regular dos procedimentos, medicamentos e insumos necessários à preservação da vida e da saúde da população geram o fenômeno da judicialização da saúde no município de Mossoró. (Entrevista concedida em 23/11/2018).

\footnotetext{
${ }^{13}$ Entrevista concedida ao canal Verbo Ead, no quadro Palavra do Professor. Disponível em: https://www.youtube.com/wat ch?v=_h770c4fAVg>.
} 
Na visão da Defensora Pública, enxergando o problema da judicialização a partir de um prisma voltado, em certa medida, aos desafios enfrentados pelos mais vulneráveis, vez que, em sua ótica, um dos pilares do problema na saúde pública são as diligências burocráticas, se referindo à complexidade existente no acesso aos serviços de saúde.

Na perspectiva da Magistrada, juíza titula da $3^{\text {a }}$ Vara da Fazenda Pública de Mossoró/RN, falta política pública direcionada bem como interesse dos gestores:

Quando um cidadão vem postular em juízo é porque não obteve sucesso na realização de determinado procedimento ou recebimento de medicamento pela Administração Pública. Destaco como principais fatores para o fenômeno da judicialização da saúde a ausência de política pública na área, bem como a ausência de interesse para melhoria do serviço disponibilizado à população (Entrevista concedida em 01/12/2018).

Corroborando esse entendimento, Machado (2011) avalia que essa tendência de judicialização subverte a lógica da criação de políticas públicas objetivando a universalidade, a integralidade e a equidade na prestação do serviço.

Em segundo momento, interrogou-se o porquê de a população buscar o judiciário quando necessita realizar um procedimento já fornecido pelo Sistema Único de Saúde. Na visão de uma professora do Curso de Direito da Universidade do Estado do Rio Grande do Norte:

A falta de continuidade das políticas públicas de saúde, seja por ausência ou desorganização no planejamento ou até mesmo pelas consequências da judicialização ensejam essas situações.

A busca pela efetivação do direito fundamental à saúde não se tornou uma escolha para a população, mas, sim, uma necessidade.

Ocorre que, além dos recursos que viabilizam a implantação da política pública de saúde serem finitos e cada vez mais escassos, demandando um planejamento cada vez mais eficiente dos entes públicos, o fenômeno da judicialização e os bloqueios de numerários dela decorrentes tem gerado uma instabilidade na programação financeira dos entes públicos. (Entrevista concedida em 23/11/2018).

O aspecto da desorganização e falha no planejamento, abordado pela Professora, foi mencionado de forma detalhada pelo Procurador do Município:

90\% da população mossoroense, quando é problema traumatológico, é acidente de moto, acidente de carro, mas 99\% é acidente de moto. Ficam aqui no Tarcísio Maia, não tem dinheiro pra isso, porque o Estado do RN é um convenio, estado e município, o estado não ta vindo, e aquilo que Mossoró recebe é bem pouquinho. Diante dessa situação as pessoas se veem na necessidade de judicializar, e quando é judicializado é mandado para hospital para ser operado em natal. Inclusive nós tivemos uma audiência na justiça federal, veio todo o pessoal do estado, Secretário de saúde, inclusive, e reconheceu que Mossoró, não está recebendo dinheiro, está sobrecarregando só o município (grifou-se e entrevista concedida em 18/11/2018).

A Defensora Pública, por sua vez, também descreveu a falha no planejamento, anteriormente apontado pelos demais entrevistados, como sendo uma das causas que levam a população a judicializar por um serviço, em tese, regularmente fornecido pela rede pública de saúde:

A grande demanda judicial na área da saúde ocorre em virtude da falha na prestação do serviço, ocasionada pela deficiência no planejamento e na comunicação entre os diversos setores que compõem a rede, pelo descumprimento e/ou falta de fiscalização dos termos de cooperação técnica e financeira celebrados entre os entes, assim como dos contratos e convênios firmados com prestadores privados.

Desta feita, considero que a efetiva necessidade de submissão ao tratamento de saúde e a ausência de qualquer previsão para a prestação do serviço no âmbito do SUS, seja em razão da falta de prestadores credenciados na própria rede municipal, da inefetividade dos sistemas de regulação e das imensas filas de espera, que resultam em sequelas irreversíveis aos usuários, são os principais fatores que geram essa busca pelo Judiciário, a fim de obter o reconhecimento de um direito fundamental constitucionalmente assegurado. (Entrevista concedida em 23/11/2018). 
O terceiro quesito levado à apreciação dos entrevistados diz respeito a quais os desafios enfrentados pela administração pública na implementação/manutenção de políticas públicas de saúde. Nesse tópico, o tema planejamento foi novamente o alvo dos entrevistados. Como se infere das colocações da Defensora Pública:

Acredito que os desafios giram em torno do planejamento e dos entraves burocráticos que dificultam tanto a implementação quanto a manutenção, de maneira contínua e regular, dessas políticas públicas. A deficiência na interligação dos sistemas de comunicação entre os diversos setores que compõem a rede também dificulta sobremaneira esse funcionamento, além da falta de fiscalização dos contratos e convênios celebrados com prestadores privados e do correto gerenciamento das verbas públicas destinadas à saúde (Entrevista concedida em 23/11/2018).

Além do planejamento, a ausência de fiscalização foi um dos fatores apontados como um dos desafios a serem implementados pelos gestores para um melhor aproveitamento do sistema de saúde pública municipal.

No decorrer da pesquisa, percebeu-se que, nos processos judiciais, quando intimado a se manifestar sobre o pedido inicial, o Município de Mossoró/RN, por seus procuradores, permanece inerte, fazendo com que o magistrado se utilize dos meios legais, dentre eles o bloqueio de verbas públicas, para dotar de efetividade suas decisões. Diante dessa situação, foi questionado aos entrevistados, por que o Município, em regra, não busca a conciliação nos litígios em que é demandado.

O tema foi tratado com cautela pelo Procurador do Município:

Geralmente, os juízes estão marcando, antes de dar a tutela, de deferir a tutela, chama o município e nós estamos negociando.

Aqui foi criado um setor de regulação de cirurgias eletivas, aqui na secretaria municipal de Mossoró. E geralmente os juízes nos dão 15 dias, 10 dias, para que, se o município, durante esses 10 dias, não fizer essas cirurgias, automaticamente marca aquela famosa audiência de conciliação, e aí dentro desse prazo o juiz já defere a liminar e, automaticamente, o bloqueio. Para você ter uma ideia, aconteceram muitos bloqueios nisso, mas ultimamente, principalmente agora no ano de 2018, isso diminuiu muito. Por que? Por conta dessa Central de Regulação. Mas, quando se trata de emergências, muitas vezes o judiciário não espera não. Ele já defere, automaticamente vai pra fazer a cirurgia. Mas isso já mudou em torno de $90 \%$, município através da Regulação fazer essas Cirurgias eletivas. (Entrevista concedida em 18/11/2018).

A Defensora Pública reforçou o apontamento do Procurador com relação ao gestor municipal, indicando falha na comunicação entre os órgãos municipais, bem como uma gestão direcionada à solução consensual dos conflitos:

Os motivos podem ser os mais diversos, tais como falha na comunicação entre os órgãos e setores municipais, falta de uma gestão mais voltada à solução consensual dos conflitos, falta de planejamento etc. Tal conduta ocasiona prejuízos aos usuários do sistema e ao erário público, sendo, portanto, de extrema relevância o alargamento do diálogo entre as esferas de gestão, a sociedade e os membros dos Poderes para que soluções viáveis sejam encontradas (Entrevista concedida em 23/11/2018).

Na visão da Juíza da $3^{\text {a }}$ Fazenda Pública, onde tramitam alguns dos processos relacionados à saúde de Mossoró/RN, a gestão municipal vem percebendo o prejuízo emanado pelos bloqueios oriundos dos processos de saúde, e que uma saída mais cômoda é culpar a falta de políticas públicas com a invasão do judiciário na competência de outros poderes:

Essa visão de o Município não buscar a conciliação está sendo, pouco a pouco, mitigada, pois o gestor está percebendo que uma ordem judicial de bloqueio baseada em orçamentos particulares, tomadas em grandes proporções, só faz aumentar a impossibilidade de implementação de políticas públicas e poder realizar planejamento nessa área, com a redução de custos. Talvez pelo fato de o Judiciário possuir o poder-dever de resolver o litígio, afigura-se mais confortável para a Administração justificar a ausência de implementação de políticas públicas, sob o fundamento de que o Judiciário está invadindo competência de outro Poder e que, por esse motivo, não lhe dá margem para efetuar o planejamento (Entrevista concedida 01/12/2018). 
Com base nos dados colhidos durante a pesquisa, aferiu-se que as despesas decorrentes de ordens judiciais relativas a questões de saúde, em 2017, somam $\mathrm{R} \$ 1.891 .716,52$. Frente a essa realidade, inquiriu-se os respondentes sobre quais as consequências da alocação (destinação) de verbas públicas por parte do judiciário.

Na visão da Defensora Pública, a alocação de verbas acarreta desarmonia na gestão do orçamento público. Todavia, ressalta que as decisões judiciais se fundamentam na própria Constituição Federal, não sendo, o princípio da reserva do possível, exemplo de óbice apto a impedir a destinação de verbas para fins de assegurar o exercício do direito à saúde pelo cidadão. Veja-se:

Essa alocação de verbas públicas por parte do Judiciário pode ocasionar um descompasso na gestão do orçamento da saúde, entretanto, é importante pontuar que as ordens judiciais encontram respaldo na Constituição da República, em razão da proteção integral assegurada ao direito fundamental à saúde, que se sobrepõe ao orçamento e suas regras (Entrevista concedida em 23/11/2018).

Seguindo o mesmo raciocínio, sob o prisma da Procuradoria Municipal, o gestor se vê obrigado a retirar recursos de outras áreas prioritárias, como a própria folha de pagamento de servidores, conforme apontado pelo Procurador, para suprir a carência no âmbito da saúde pública, o que tem prejudicado uma gestão equânime por parte do executivo municipal.

Isso é muito grave. (...) Diante dessa demanda, desses bloqueios judiciais, isso é uma catástrofe. Porque só a título de exemplo e simbolismo: Digamos que tem $\mathbf{R} \$ \mathbf{1 . 0 0 0 . 0 0 0 , 0 0}$ (um milhão) aqui, de uma verba, pra fazer uma reforma de uma escola, uma reforma qualquer, um investimento a serviço do povo.

O juiz, quando vai bloquear, ele não quer nem saber. É Município? Ele vai em todas fontes, e bloqueia todas as fontes. E o Município fica até sem folha de pagamento, muitas vezes aí, teve que pedir ao juiz que não bloqueasse, deixasse virar o mês, porque senão a folha de pagamento ia ser atingida. Portanto, resumindo, é uma catástrofe para Estado e Município. (Entrevista concedida em 18/11/2018).

Por fim, considerando a situação atual da saúde pública na cidade de Mossoró-RN, indagou-se aos entrevistados, com base na vivência profissional particular de cada um, quais mudanças deveriam ser feitas para que a política pública relacionada ao fornecimento de cirurgias eletivas seja classificada como efetiva.

Na opinião da Defensora Pública, há a necessidade de maior organização administrativa e distribuição de recursos, bem como que o ente público contrate prestadores locais e fiscalize suas atividades:

Embora seja difícil citar todas as mudanças imprescindíveis para a efetivação do fornecimento de cirurgias eletivas no âmbito do município, é possível fazer alusão à necessidade de organização administrativa do sistema de saúde no Município, mediante a realização de um diagnóstico da real demanda e a articulação entre os diversos setores, a fim de promover o diálogo entre os gestores de cada área do sistema de saúde, para que sejam traçadas estratégias de atendimento mais eficazes. É importante também que se priorize a contratação de prestadores no próprio município e que haja a fiscalização dos serviços por eles prestados (Entrevista concedida em 23/11/2018).

Ainda sobre o tema, a Magistrada aponta a imprescindibilidade de uma melhor definição de responsabilidades, além de, mais uma vez, cooperação entre os entes são as mudanças obrigatórias para a efetivação de uma política pública eficiente:

A partir do momento em que o Supremo Tribunal Federal estabeleceu a responsabilidade solidária entre o Município, Estado e União Federal no trato da saúde, cabendo ao autor escolher contra quem deseja litigar, tal fato ensejou um desequilíbrio nas atribuições de cada ente federativo. Exemplificando, quando uma pessoa hipossuficiente procura a Defensoria Pública Estadual para ingressar com ação judicial, esta não irá formular pedido em desfavor do Estado, o que leva ao direcionamento de ações em face do Município (Entrevista concedida 01/12/2018). 
Assim, na perspectiva da magistrada, somente com o estabelecimento de regras de competência claras e objetivas entre as três esferas do Executivo poder-se-á iniciar uma política pública que seja mais efetiva e com mais equilíbrio, ou seja, deixando para o Município procedimentos mais simples e de menor custo, os de média complexidade com os Estados e os de alta complexidade com a União.

\section{Considerações Finais}

Diante do cenário atual da saúde pública local, o crescimento do fenômeno da judicialização da saúde em Mossoró/RN nos casos que envolvem a realização de procedimentos cirúrgicos, iniciou-se a pesquisa buscando-se compreender o referido fenômeno, suas causas, consequências, sujeitos envolvidos e aspectos relevantes acerca da questão.

A realização de pesquisa em dados processuais, bem como a análise da literatura atinente ao tema, além da realização das entrevistas, possibilitou esclarecer os pontos controvertidos, como o porquê de a conciliação judicial não ser a regra em que o ente público municipal é demandado, ou a necessidade do bloqueio de verbas públicas como forma de obtenção do resultado prático equivalente pleiteado pelas vias judiciais.

Constatou-se a descontinuidade das políticas públicas como sendo um dos fatores principais a ensejar a judicialização do direito à saúde. Isso decorre do pouco ou mal planejamento dos gestores públicos, como também da grande demanda de cirurgias face ao orçamento escasso. A justificativa orçamentária do ente municipal esbarra no direito constitucional do cidadão, pelo que se verifica, aqui, um conflito aparente entre os princípios do mínimo existencial e o da reserva do possível.

O levantamento de dados obtidos nos processos analisados, cuja planilha demonstra os valores de procedimentos cirúrgicos orçados antes e após audiência conciliatória comprova que a conciliação é, indubitavelmente, um dos meios pelo qual o erário público seria menos onerado. A alternativa de economicidade deveria, por comprovada eficácia, ser adotada em todos os casos envolvendo a judicialização do direito à saúde, isso porque, conforme as evidências atestadas na pesquisa processual, a conciliação, nos casos examinados, possibilitou economia de mais de 30\% (trinta por cento) do valor inicial que seria gasto com o procedimento cirúrgico.

Assim, conforme o que se pôde averiguar, é necessário maior organização administrativa por parte dos gestores públicos, o que levaria, paulatinamente, à melhoria da prestação dos serviços públicos de saúde e, consequentemente, à diminuição no número de demandas ajuizadas em face do Município.

A cooperação entre os sujeitos partícipes dos processos também é de fundamental importância para que se tenha uma política pública regularmente estabelecida e em devido funcionamento. Nesse ponto, o projeto "SUS Mediado", citado pela representante da Defensoria Pública Estadual, deve ser estudado e, se possível, implementado na cidade, a fim de que seja assegurado o acesso integral e universal aos serviços realizados pelo Sistema Único de Saúde.

Portanto, conclui-se que tornar a judicialização uma ferramenta exclusiva para solucionar os problemas sociais não é o caminho mais sensato a se tomar, vez que, quando um cidadão afirma ter um direito, ele não o possui isoladamente, mas sim em consonância com toda a sociedade, o que deve ser considerado tanto pelas instituições de defesa de direitos do cidadão, quanto pelo próprio judiciário quando do exercício da prestação jurisdicional.

Ademais, a despeito das alternativas propostas à judicialização da saúde, é possível vislumbrar outras direções de pesquisa para estudos futuros, a fim de que a produção acadêmica ofereça suporte teórico suficiente para influir inclusive nas decisões políticas dos gestores públicos. Dentre essas vertentes, evidenciam-se: a tecnologização das atividades como obstáculo ao acesso às políticas públicas de saúde em tempos de pandemia, considerando a vulnerabilidade da população-alvo; a necessidade de desburocratização do acesso à saúde local, com a redução de etapas, dada a dificuldade da população em utilizar serviços básicos essenciais; a indispensabilidade da criação de órgão ou entidade composta por cidadãos comuns da sociedade civil cuja função seja fiscalizar e publicizar a origem e direcionamento dos valores destinados à saúde pública local. 
Research, Society and Development, v. 10, n. 4, e37410414331, 2021

(CC BY 4.0) | ISSN 2525-3409 | DOI: http://dx.doi.org/10.33448/rsd-v10i4.14331

\section{Referências}

Arretche, Marta T. S. (1999). Tendências no estudo sobre avaliação. In: Rico, E. M. Cortez/IEE, 29-39.

Brasil. Constituição (1988). Constituição da República Federativa do Brasil. Brasília, DF: Senado Federal: Centro Gráfico, 1988.

Brasil. (1990). Lei n. 8080, de 19 de setembro de.

Brasil. (1990). Lei n. 8.142, de 28 de dezembro de.

Brasil. (2016) Portaria n. 399, de 22 de fevereiro de.

Brasil. Sistema de Gerenciamento da Tabela de Procedimentos, Medicamentos e OPM do SUS. Ministério da Saúde.

Carvalho, Sabrina Nasser de. (2016). Processos coletivos e políticas públicas: mecanismos para a garantia de uma prestação jurisdicional democrática. São Paulo: Editora Contracorrente.

Di Pietro, Maria Sylvia Zanella. (2007). Direito Administrativo. (20a ed.), Atlas.

Falchi, Raquel Anthonisen. (2014). A judicialização da saúde no município de Pelotas. 119 p. Dissertação (Programa de Pós-Graduação em Política Social) Universidade Católica de Pelotas, Pelotas.

Fonte, Felipe de Melo. (2013). Políticas públicas e direitos fundamentais: elementos de fundamentação do controle jurisdicional de políticas públicas no Estado Democrático de DireitoSaraiva.

Godoy, A. S. (1995) Introdução a pesquisa qualitativa e suas possibilidades. Revista de Administração de Empresas, 35(2), 57-63.

Rio Grande do Norte. (2018). Lei n. 3.104, de 08 de janeiro de 2014.

Rio Grande do Norte. (2018). Lei n. 3.526, de 12 de janeiro de 2017.

Jannuzzi, Paulo de Martino. (2017). Indicadores sociais no Brasil: conceitos, fontes de dados e aplicações. (6a ed.), Editora Alínea.

Machado, Marina Amaral de Ávila, Acurcio, Francisco de Assis, Brandão, Cristina Mariano Ruas, Faleiros, Daniel Resende, Guerra Júnio, Augusto Afonso, Cherghiglia, Mariângela Leal \& Andrade, Eli Lola Gurgel. Judicialização do acesso a medicamentos no Estado de Minas Gerais, Brasil. Rev. Saúde Pública, 45(3).

Mileski, H. S. (2011). O controle da gestão pública. (2a ed.), Fórum.

Muller, P. (2018). As políticas públicas. Eduff.

Oliveira, M. M. de. (2007). Como fazer pesquisa qualitativa. Vozes.

Rosa, M. V. de F. P. do C., \& Arnoldi, M. A. G. C. (2008). A entrevista na pesquisa qualitativa: mecanismos para validação. Autêntica.

Secchi, Leonardo. (2016). Análise de políticas públicas: diagnóstico de problemas, recomendação de soluções. Cengage Leaning.

Soares, Evandro da Silva (2021). A influência da judicialização das políticas públicas de saúde na execução do orçamento público: estudo de caso do Distrito Federal. 2017. 121 f. Dissertação (Mestrado em Direito Constitucional) - Instituto Brasileiro de Ensino, Desenvolvimento e Pesquisa, Brasília.

Sousa, Aione Maria da Costa. (2013). O público e o privado no sistema de saúde em Mossoró - RN: as contradições para a efetivação da universalidade. Recife. 299 f. Tese (doutorado) - UFPE, Centro de Ciências Sociais Aplicadas, Programa de Pós-graduação em Serviço Social.

Prefeitura Municipal (Mossoró/RN). (2018). Portal da Transparência da Prefeitura Municipal de Mossoró/RN: Gastos Diretos Por Tipo de Despesa. 